\title{
Teaching Indonesian Ambiguous Words on BIPA
}

\author{
Johanna B. S. Pantow \\ Universitas Terbuka \\ johanna@ecampus.ut.ac.id
}

\begin{abstract}
Indonesian language has huge of ambiguous words. These words are confused for foreigners whom learned Indonesian. This paper will discuss some roads to teach ambiguous words which mostly called homonyms. Homonyms are words sound and spelling the same however they have different meaning. Integrative methods and techniques are needed in teaching homonyms to BIPA students who are foreigners. This study will also show some examples of materials for teachers to prepare their teaching materials. Moreover, it will explore how the roads to implement on teaching to BIPA students.
\end{abstract}

Keywords: BIPA Ambiguous words, learning

\section{PENDAhuluan}

Tiga komponen penting dalam mencapai tujuan pembelajaran bahasa Indonesia untuk pembelajar asing (BIPA). Komponen pertama meliputi pembelajar, kedua materi dan ketiga proses pembelajaran. Ketiga komponen ini saling terkait serta tidak boleh dipisahkan. Komponen pertama, pembelajar adalah subjek dalam pembelajaran. Komponen kedua, materi adalah bahan ajar yang dipersiapkan pengajar untuk meningkatkan penguasaan bahasa Indonesia pembelajar. Materi yang disiapkan perlu memenuhi kriteria kebutuhan pembelajar serta meningkatkan kemampuan pembelajar dalam berbahasa Indonesia dengan lancar. Proses pembelajaran dilakukan sesuai dengan kebutuhan pembelajar dan materi yang disiapkan pengajar. Strategi pembelajaran bahasa yaitu alat-alat untuk mencapai tujuan pembelajaran, materi yang diajarkan, maupun metode pengajarannya seperti dikemukan oleh N.P.W.A Sari Utama dkk [1]. Selanjutnya, Citra Megawati 2014 mengemukakan bahwa pembelajaran adalah sebuah proses komunikasi antara pembelajar, pengajar dan bahan ajar.[2] Dalam proses pembelajaran, pengajar dan pembelajar berintegrasi aktif untuk mencapai tujuan pembelajaran. Asqina Mawadati N.S dkk [3] berpandangan bahwa dalam pembelajaran Bahasa Indonesia bagi Penutur Asing (BIPA), seorang pengajar harus mempunyai kemampuan dalam manyampaikan materi ajar, mengelola kelas, dan menggunakan media pembelajaran yang tepat sehingga dapat memberikan penilaian dengan baik dan profesional. Teknik pembelajaran diterapkan dengan berbagai jenis sehingga pembelajar terlibat dalam penggunaan bahasa Indonesia dengan aktif. Penetapan materi, metode, tehnik dan model belajar harus mengacu pada kebutuhan pembelajar serta kemampuan mereka. Beberapa aspek yang perlu diperhatikan pengajar dalam proses pembelajaran; a. berikan wahana bagi pembelajar mempraktikan kaidah-kaidah bahasa agar pembelajar mengetahui pencapaian pembelajarannya; b. berikan kesempatan bagi pembelajar untuk berkomunikasi secara alami; c. berikan waktu kepada pembelajar untuk meningkatkan kemampuan berbahasanya; d. 
berikan kepada pembelajar materi faktual sesuai kebutuhan mereka. Selain itu pengajar pun perlu menyiapkan bahan evaluasi belajar dan program. Muhammad Badrus Siroj[4] berpendapat bahwa perencanaan dan proses pembelajaran hendaknya dikembangkan secara sistematis, seksama, serta dijangkaukan untuk menumbuh kembangkan motivasi dan kesadaran pembelajar pada target pembelajaran yang jelas.

Dalam berbagai kesempatan diskusi, seminar, dan tulisan banyak topik yang membahas tentang kemampuan berbahasa Indonesia para pembelajar BIPA. Mereka menemukan kesalahan yang dibuat para pembelajar BIPA. Imam Suyitno[5] mengemukakan kesalahan penggunaan sinonim dalam kalimat. Selanjutnya, Dini Restiyanti Pratiwil, Laili Etika Rahmawati, Miftakhul Huda [6] menemukan kesalahan berbahasa pada tulisan mahasiswa Thailand dalam pembelajaran pramenulis dapat diklasifikasikan salah satu kesalahan dalam pemilihan kata (diksi), meliputi empat aspek (a) pemilihan kata sifat; (b) penghilangan imbuhan; (c) kesalahan penggunaan kata sebagai pelengkap; (d) kesalahan penggunaan kata sebagai predikat; dan (e) kesalahan penentuan subjek temuan. Selain itu ditemukan juga oleh Sri Rejeki dkk [7] bahwa pembelajar BIPA melakukan kesalahan fonologis, kesalahan sintaksis, dan kesalahan leksikon.

Proses pembelajaran bahasa Indonesia secara formal perlu dilakukan dengan model pembelajaran yang mengintegrasikan empat keterampilan berbahasa. Kegiatan pembelajaran bahasa, harus berpusat pada mereka yang belajar bahasa. Dalam proses pembelajaran, pengajar wajib mengintegrasikan empat keterampilan berbahasa sehingga pembelajar mampu menyimak, berbicara, membaca dan menulis. Pembelajaran dilakukan secara terpadu, maksudnya sajian materi keterampilan berbahasa, kosakata, dan catatan budaya tidak dilakukan secara terpisah seperti dikemukakan Eko Widianto.[8]

Berbagai literatur telah membahas tentang kesulitan orang asing mempelajari bahasa Indonesia. Kesulitan memilih kosa kata serta homonim dalam semantik serta lainnya merupakan kesulitan orang asing dalam BIPA. Menurut Asul Wiyanto [9] dalam bukunya bahwa kalimat ambigu dapat menghambat kelancaran komunikasi karena pihak penerima (pendengar dan pembaca) dapat menafsirkan arti yang berbeda dengan arti yang dimaksud oleh pembicara atau penulis. Literatur tentang pembelajaran homonim bahasa Indonesia belum banyak yang membahas walaupun ada beberapa tesis dan makalah yang membahas homonim ditinjau dari kesulitan memilih kosa kata dan penggunaannya dalam konteks semantik. Berbeda dengan artikel ini membahas tentang pembelajaran homonim bagi pembelajar BIPA. Studi ini dapat menambah bahan inovasi pembelajaran bahasa Indonesia sebagai model pembelajaran kosa kata yang terintegrasi dalam berbagai konsep. Konsep model pembelajaran penguasaan homonim akan sangat membantu pembelajar BIPA dalam empat keterampilan berbahasa. Konsep pembelajaran ini menawarkan kepada pembelajar penguasaan kosa kata dalam konstruksi kalimat, wacana, prosa dan pantun maupun lagu.

\section{METODE}

Metode deskriptif kualitatif diterapkan dalam penelitian ini. Metode kualitatif berusaha memahami dan menafsirkan makna suatu peristiwa interaksi tingkah laku manusia dalam situasi tertentu menurut perspektif peneliti sendiri, seperti yang ditulis Imam Gunawan.[10] Pengumpulan data dilakukan dengan beberapa cara yaitu: mempelajari beberapa dokumen berupa buku terkait judul artikel, jurnal terkait topik, observasi para pembelajar BIPA, serta wawancara dengan beberapa orang yang terkait dalam proses pembelajaran BIPA. Penelitian ini menggunakan sumber data para pengajar BIPA dalam pelatihan dan seminar. Selain itu, 
para pembelajar BIPA yang menghadiri pelatihan serta seminar BIPA. Validasi data dilakukan dengan menggabungkan data dari berbagai sumber, observasi serta wawancara.

\section{HASIL DAN PEMBAHASAN}

The successful of learning for foreign students is not only determined by the model of learning, but also the role of learning media. The real object of learning media is selected as the strategic step in order that the teaching learning process can be received by the students well, menurut Nugraheni Eko Wardani, Ch. Evy Tri Widyahening, Raheni Suhita.[11] Mereka lebih lanjut berpendapat bahwa Learning media of real objects using wayang wong can fulfill the needs of students to reach, recode, reinforce, and rehearse, so the learning material is easy to be understood.

Isnaini, Mohammad [12] berargumentasi bahwa salah satu cara yang dapat dilakukan guru adalah dengan memanfaatkan media pembelajaran. Media dapat membuat pembelajaran menjadi lebih menarik, materi lebih mudah dipahami, dan aktivitas kelas lebih bervariasi. Secara lebih khusus, media yang dapat dengan mudah dimanfaatkan guru adalah media gambar-narasi. Media gambar-narasi merupakan media gambar yang terintegrasi dengan topik yang sedang dipelajari. Melalui media gambar ini, pemelajar dapat membuat narasi.

Oleh karena pendapat di atas, maka pengajaran bagi pembelajar BIPA akan sangat efektif bila menggunakan media. Dalam artikel ini, penulis mengemukakan beberapa media yang dapat dimanfaatkan. Pertama, Daftar kosa kata homonim merupakan salah satu alat yang tepat digunakan bagi pembelajar bahasa asing dalam mengenal homonim bahasa Indonesia. Daftar ini merupakan sejumlah homonim yang tertulis dengan maknanya. Setiap homonim yang telah ditulis dengan maknanya kemudian dibahas bersama pembelajar dengan contoh kalimat seperti yang terlihat pada kotak di bawah ini.

Pengajar menggunakan daftar tersebut untuk membantu pembelajar mengenal homonim. Kemudian meminta mereka untuk menyusun kalimat pendek dengan homonim yang mereka temukan sendiri dalam kamus atau daftar yang telah disiapkan pengajar. Aktifitas ini dapat dilakukan secara berpasangan atau kelompok. Homonim yang tercantum dalam daftar di atas dapat digunakan untuk mengajarkan tentang kosa kata yang bermakna beda tapi pelafalan dan ejaannya sama yang membingungkan pembelajar. Daftar tersebut dapat membantu guru mengajarkan perbedaan makna dari kosa kata yang sama dalam konteks yang jelas dan tepat sesuai makna ganda atau lebih. Pembelajar dapat membedakan makna kata tersebut saat mereka disuguhi contoh penggunaan homonim dalam kalimat atau konteks. Berikut contoh kata ambigu atau homonim. Daftar homonim harus disertai makna masing-masing sehingga pembelajar tidak menghafal kosa kata namun paham maknanya dalam konteks.

\section{Gambar 1. Contoh Homonim}

Tanda(1) baca digunakan dalam kalimat, tanda(2) tangan untuk mensahkan sebuah dokumen dan tanda(3) mata sudah kuberikan padanya sebelum kami berpisah.

1. Tanda bermakna titik (.) Tanda Koma (,) Tanda Seru (!) Tanda Titik Koma (;) Tanda Titik Dua (:) ... Tanda Hubung (-) ... Tanda Elipsis (...) Tanda Tanya (?)

2. Tanda bermakna pengesahan dokumen/surat/wasiat/sertifikat

Bagi(1) saya, bagi(2) dua kue sekecil itu tidak mungkin.

1. Bagi bermakna menurut atau pendapat

2. Bagi bermakna pembagian 
Bisa(1) saja semua itu disembuhkan bila bisa(2) gigitan tawon itu dikeluarkan.

1. Bisa bermakna mampu atau dapat

2. Bisa bermakna racun

Saya tahu(1) bahwa tahu(2) Sumedang itu enak dan legit.

1. Tahu bermakna mengetahui atau mengerti

2. Tahu bermakna jenis makanan khas Sumedang

Gunakan gambar dalam pembelajaran kosa kata homonim. Media gambar sangat baik karena pembelajar akan langsung melihat apa yang dimaksud dengan homonim yang sedang mereka pelajari.

Gambar 2. Contoh Homonim terkait Bagian Tubuh
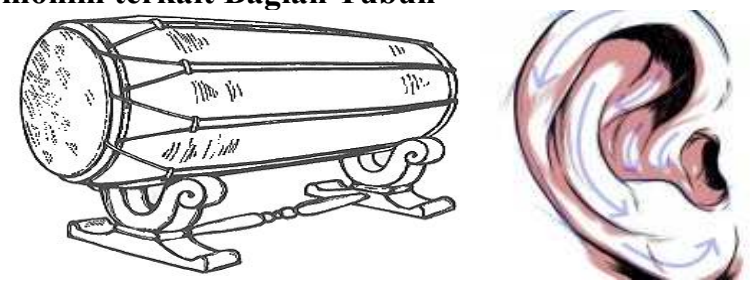

Suara gendang sangat keras membuat gendang telinga saya sakit.
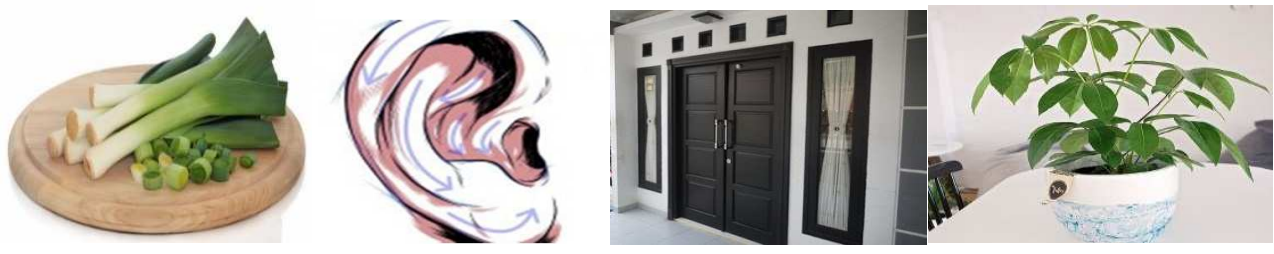

Daun bawang banyak di dapur, daun telinga tertempel dekat pipi setiap orang dan daun pintu menempel di bagian rumah serta daun hijau tergantung pada batang pohon

Gambar 3. Contoh Homonim terkait Bagian Tubuh
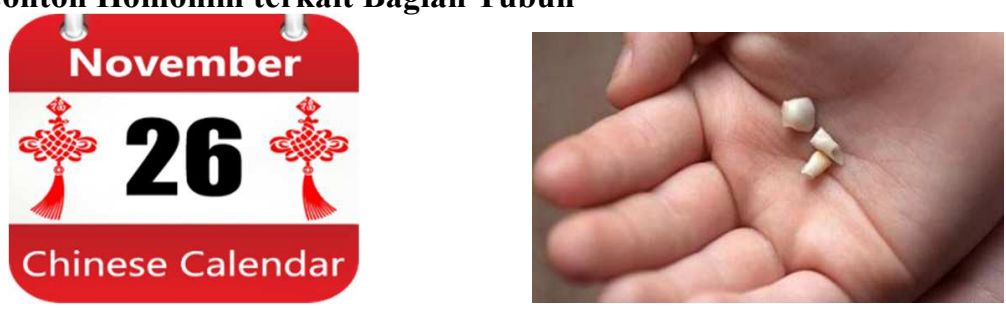

Tanggal 26 November ulang tahun Ari ke 6 dan pada hari itu gigi Ari tanggal 2 biji.

Gunakan kalimat-kalimat di atas untuk mengajarkan perbedaan makna dari kata yang sama dengan lafal yang sama kepada pembelajar sehingga mereka paham dan tidak membingungkan. Akan lebih baik lagi bila guru menggunakan beberapa gambar sebagai alat bantu untuk menjelaskan makna kosa kata yang ambigu. 


\subsection{Contoh Prosa untuk mengajarkan homonim}

Daun hijau tertempel di dahan, daun pintu menempel di rumah.

Daun muda laris dan menarik, mudah tergoda pemuda ganteng.

Bang Ali duduk di bawah pohon menunggu istrinya dari bank.

Duduk seorang diri menunggu mentari berbayar di bawah cahaya mentari.

Manis sekali gadis itu yang sedang minum teh manis.

Hati berbunga duduk berdua di bulan muda di bawah bulan purnama.

Bunga di taman yang indah mengingatkan bunga tabunganku.

Mata hati terpancar berbinar di mata sang gadis manis itu.

Mata air mengucur jernih di tengah air mata yang mengalir.

Air mengalir di kali Cisadane, banyak kali dia merenung di situ.

Mereka memulai rumah tangga dengan menaiki anak tangga di rumah itu.

Mereka naik tangga sambil bernyanyi gembira karena baru saja naik pangkat.

Penyanyi yang sedang naik daun itu naik pesawat menuju Jakarta.

Jatuh hatinya mendengar harga gabah jatuh.

Dia jatuh sakit karena jatuh dalam Ujian Akhir Semester.

Teriknya mentari membuat udara panas, hatinya panas melihat tingkah orang itu.

Bagian muka gedung itu besar dan muka para tetamu riang gembira.

Mereka membeli amplop dan diberi amplop itu kepada petugas.

Sinta semakin mengurus sehingga Ibunya sibuk mengurus Sinta.

Dara memelihara burung dara yang lucu itu.

Penutup kepala menghindari panas, kata penutup menyelesaikan acara.

Setelah membaca dan memaknai prosa di atas, mintalah para pembelajar untuk membahas dalam kelompok arti homonim dalam prosa tersebut. Setelah itu, minta setiap kelompok membuat rangkaian homonim yang membentuk kalimat berirama pantun atau karya sastra sederhana.

\subsection{Contoh Syair lagu Raisa}

Saat air lebih langka dari air mata

Saat udara harus kau beli

Saat bunga membumbung dan bunga tinggal cerita

Akankah akhirnya kita sadari

Pengajar dapat menggunakan lagu atau syair lainnya sebagai alat bantu dalam memastikan pembelajar benar-benar paham tentang homonim. Mereka dapat melatih diri sendiri dengan mendengarkan lagu yang mengandung homonim dalam syairnya. Pembelajar diminta membuat karya sastra pendek dengan menggunakan homonim.

\subsection{Contoh wacana untuk mengajarkan homonim}

Gunakan wacana berikut dengan meminta pembelajar berkelompok menemukan homonim pada wacana berikut. Para pembelajar menuliskan homonim dan buat kalimat baru dengan homonim yang telah mereka temukan. Mintalah kelompok lain mengomentari tulisan masingmasing kelompok secara bergantian. Diskusikan hasil akhir dari tulisan setiap kelompok. 
Banyak hal yang telah saya alami di dunia ini. Salah satunya belajar berbagai bahasa dengan kosa kata yang memusingkan dan membingungkan. Bahasa Indonesia termasuk bahasa yang memiliki kata ambigu atau homonim.

Homonim adalah kosa kata yang berlafal dan ejaannya sama namun bermakna beda. Beberapa kosa kata yang termasuk dalam homonim seperti tertulis dalam berbagai kalimat berikut. "Kami setiap hari Senin pagi apel di halaman kantor dan setelah itu makan apel."

"Kanak-kanak itu berbaris di halaman Taman Kanak-kanak setiap pagi."

"Asri sekali taman itu kata Asri."

"Mata pelajaran Matematika sangat saya sukai namun bahasa Indonesia membuat mata saya sakit."

"Amat rajin makan buah-buahan yang membuat dia amat sehat."

"Mereka orang beruang dan pencinta beruang."

"Rapat telah ditutup dan semua pintu ruang rapat ditutup rapat."

"Para pejabat teras sedang rapat di teras rumah dinas gubernur."

"Keadaannya gawat maka di bawahlah dia ke gawat darurat di sebuah rumah sakit."

"Kursi itu diperebutkan banyak orang yang duduk di kursi itu."

Homonim menarik dipelajari dan tidak akan membingungkan bila kita tahu maknanya. Pengajar perlu menggunakan berbagai metode dan teknik dalam mengajarkan homonim kepada pembelajar seperti menemukan homonim dalam wacana.

Selain berbagai cara di atas pengajar dapat juga menerapkan beberapa teknik pembelajaran homonim di kelas BIPA seperti berikut.

1. Menyiapkan daftar homonim dan maknanya dalam kalimat pada karton.

2. Membagi kelas dalam kelompok dengan menebak makna homonim yang tertulis pada karton yang dibagikan kepada setiap kelompok.

3. Menyiapkan kartu homonim dan pembelajar diminta berpasangan membuat kalimat lisan dengan kata tersebut yang bermakna berbeda satu sama lainnya.

4. Lomba menulis homonim di papan tulis oleh tim A dan tim B, minta mereka membuat kalimat dengan makna yang berbeda dari setiap homonim yang didikte oleh pengajar.

5. Siapkan kartu dengan makna yang berbeda dan pembelajar menebak homonim yang sesuai dengan makna tersebut.

\section{SIMPULAN}

Pembelajaran bahasa Indonesia bagi orang asing memerlukan metode dan teknik khusus. Untuk memampukan pembelajar menggunakan kosa kata dalam konteks kalimat, paragraf dan wacana maka pengajar perlu mempersiapkan materi yang cocok. Daftar kosa kata homonim dan maknanya adalah salah satu materi yang bermanfaat untuk digunakan dalam proses pembelajaran. Latihan dalam memahami makna kosa kata homonim dengan cara membuat kalimat pendek sesuai daftar yang disediakan. Selain itu, pengajar dapat menggunakan gambar untuk memudahkan pembelajar memahami makna homonim. Lebih lanjut, pengajar dapat menggunakan prosa yang mengandung homonim sehingga pembelajar semakin paham dengan homonim. Lagu juga dapat dimanfaatkan sebagai alat untuk mengajarkan homonim. Wacana menjadi bagian yang mendukung pengajar dalam mengajarkan homonim kepada pembelajar asing. 


\section{REFERENCES}

[1] N. P. A. W. Sari, I. M. Sutama, and I. D. G. B. Utama, "Pembelajaran Bahasa Indonesia Bagi Penutur Asing (BIPA) di Sekolah Cinta Bahasa, Ubud, Bali," eJournal Prodi Bhs. dan Sastra Indones. Undiksha, vol. 5, no. 3, 2016.

[2] C. Megawati, "Pengembangan Media Pembelajaran Bipa Tingkat Menengah Melalui E-Book Interaktif Di Programincountry Universitas Negeri Malang Tahun 2014," Nosi, vol. 2, no. 1, pp. 62-70, 2014.

[3] A. M. N. Setiawan, A. Andayani, and K. Saddhono, "the Use of Writing Learning Media for Bipa Students To Understand Local Culture," Komposisi J. Pendidik. Bahasa, Sastra, dan Seni, vol. 18, no. 1, p. 66, 2017.

[4] A. Pendahuluan, "IMPLEMENTASI MODEL TUTORIAL TERSISTEM DALAM PEMBELAJARAN BAHASA INDONESIA BAGI PENUTUR ASING DI UZBEKISTAN Muhammad Badrus Siroj," pp. 72-82.

[5] I. Suyitno, "Pengembangan Bahan Ajar Bahasa Indonesia untuk Penutur Asing (BIPA) berdasarkan Hasil Analisis Kebutuhan Belajar," Wacana, J. Humanit. Indones., vol. 9, no. 1, p. 62, 2007.

[6] S. Mengikuti and P. Pramenulis, "University Research Colloquium 2016 ISSN 24079189 KESALAHAN BERBAHASA PADA TULISAN MAHASISWA THAILAND SELAMA MENGIKUTI PEMBELAJARAN PRAMENULIS,” pp. 192-199, 2016.

[7] S. Rejeki, C. Asari, U. S. Maret, and U. N. Malang, "Ragam sapaan yang digunakan pengajar bipa."

[8] "eko widianto 2017."

[9] A. Wiyanto, No Title, I. Yogyakarta: Jogya Bangkit, 2012.

[10] "KUALITATIF Imam Gunawan."

[11] N. E. Wardani, E. T. Widyahening, and R. Suhita, "Learning Media Using Wayang Wong to Introduce Local Wisdom of Javanese Culture for The Students," J. Arts, Sci. Commer., vol. VII, no. July 2016, pp. 48-54, 2016.

[12] "PROSIDING SEMAR ( Seminar Kepakaran ) BIPA 1." 